\title{
Recurrent Neuroendocrine Neoplasm
}

National Cancer Institute

\section{Source}

National Cancer Institute. Recurrent Neuroendocrine Neoplasm. NCI Thesaurus. Code C157130.

The reemergence of a neuroendocrine neoplasm after a period of remission. 